\title{
EL PODER DE LOS BRUJOS
}

\author{
Rafael Rodríguez Díaz
}

Cuando tu abuela estaba chiquita iba con sus hermanos y primos a visitar al tío Agustín... El tío vivía en su finca de la montaña, allá en Chalchuapa... y tenía fama de brujo. Mamá Tanchito - tu abuela - se recordaba cómo el tío Agustín pedía que le dieran un pañuelo... Le hacía un nudo en la punta y formaba una especie de muñequito... con cabecita y gorrito. Después ponía el pañuelo en el suelo y le decía: $-A$ ver, segui a la Elbirita -la Elvirita era una prima de mi mamá... y el muñequito ese se ponía bien paradito y comenzaba a caminar detrás de la muchachita. La Elvirita se subía en una silla y lloraba toda asustada... El muñequito hasta saltaba tratando de alcanzar la silla.

Como este relato que me hizo mi mamá, hay tantos otros que ponen de manifiesto los "poderes" especiales que poseen ciertas personas. La Telekinesis o poder de trasladar, doblar o destruir objetos con la sola fuerza de la mente, puede ser una de las explicaciones para lo que hacía el tío Agustín. También pudo haberse tratado de una suerte de ilusionismo; algo así como la habilidad que tienen ciertos magos y prestidigitadores: hacen creer a los espectadores que los objetos se mueven o cambian de apariencia, cuando, en realidad, no se han movido de lugar o han permanecido igual.

Pero puede estar en juego también la existencia de verdaderos poderes que llamaremos mágicos porque lindan con esos terrenos 
de lo arcano, de lo misterioso. Poderes para los cuales, hoy por hoy, no existe una explicación medianamente convincente.

Hablan algunos de que ciertos sacerdotes de las culturas precolombinas tenían conocimientos, en algunas áreas, muy superiores a los que ahora poseemos. Se dice que los mayas posiblemente llegaron a dominar la desmaterialización; es decir, ese poder de desmaterializar o reducir a átomos ciertos objetos para trasladarlos luego a lugares distantes. Así construirían las grandes pirámides y templos: trasladando con la mente o desmaterializando las grandes moles de piedra. De los egipcios se dice también algo parecido.

Dado el carácter esotérico de esos conocimientos, se trasmitían y se conservaban en círculos muy cerrados. Muy posiblemente, también, la mayor parte de esa ciencia se fue a la tumba con los últimos sabios de esas culturas precolombinas o egipcias.

Pero no es descartable la posibilidad de que parte de ese acervo haya quedado como una herencia entre los sucesores de aquellos antiguos sacerdotes. Lo que pasa es que, dadas las condiciones de marginalidad que aún padecen las culturas indígenas, esos doctos conocimientos se entremezclan, muchas veces, con burdas supersticiones o, peor aún, con la charlatanería oportunista. De modo que brujos, curanderos o shamanes son catalogados, a veces con razón, como simples oficiantes de cultos satánicos.

Y en esa línea de reconocimiento (en el doble sentido de la palabra: reconocimiento como exploración y reconocimiento como reconocerle a algo o a alguien su justo valor) es que irá el presente recorrido por materiales y testimonios de la tradición oral.

\section{Los shamanes de Momostenango}

Humberto Ak'abal es un indio quiché a quien conocí en el Tercer Encuentro de Intelectuales Chiapas-Centroamérica, celebrado en la ciudad de Tapachula, Estado de Chiapas, México. Con Humberto nos hicimos amigos casi desde el primer momento y pudimos pláticar largo y tendido sobre muchos temas. Humberto me contó de su vida, de sus sufrimientos y de sus logros. 
Yo soy de Momostenango, departamento del Quiché, en Guatemala. Quedé huérfano de muy chico y tuve que ayudar a mis otros hermanos pequeños para que salieran adelante. He trabajado, sobre todo, como cargador de bultos en las terminales de buses; he cultivado la tierra... Pero me pude ir formando. Aprendi el castellano cuando tenía unos 15 años -ahora tengo treinta y cinco-; $y$, desde entonces, no he parado de leer: poesía, novela, ensayo... Soy, pues, un autodidacta.

En algún momento, entramos al tema de las peculiaridades de la cultura indígena, a la cual Humberto Ak'abal pertenece de todo corazón.

En mi pueblo de Momostenango saben que tengo el don de la poesía; pero, fijate, que mi gente no dice que yo soy poeta... Dicen que soy la poesía de todos ellos. Yo pongo en palabras lo que todos producen y crean en cuanto a ideas e imágenes poéticas. La poesía es creada por todos... sólo que hay uno, en este caso yo, que tiene la facultad de traducir en palabras eso que, entre todos, ha sido concebido...

Yo sé que hay conocimientos y facultades que yo nunca voy a tener... porque pertenecen a otros cargos y funciones. Por ejemplo, mi abuelo y mi tío abuelo son los hamanes o sacerdotes... Ellos tienen conocimientos que van a trasmitir a los que los suceden en sus cargos... y a nadie más.

Humberto Ak'abal es un personaje sorprendente. Físicamente, más que un indígena puro es ya un mestizo; incluso, su vivacidad y su humor siempre presto hasta para bromas pesadas - como cuando en el curso de una plática me equivoqué y, en vez de sonidos del bosque dije ruidos del bosque, Humberto se rió de mi descaradamente-, se alejan un tanto del comportamiento retraído y hasta hosco de ciertos indígenas con respecto al ladino o al blanco.

Con Humberto me sucedió algo similar a lo que experimenté con Rigoberta Menchú. Ante Rigoberta - a quien escuchaba por primera vez en un hotel de San Salvador- me sentí vivamente emocionado y orgulloso. Fue tan sencilla pero también tan lúcida su intervención, que yo creí estar ante una auténtica sacerdotisa maya, impartiendo su palabra, su enseñanza sabia. 'Ella es la here- 
dera de aquella sabiduría ancestral; en ella se han encarnado y han continuado su labor los antiguos sacerdotes y shamanes mayas', me decía a mí mismo, orgulloso de estar plenamente sintonizado con su mensaje. Fue más o menos la misma impresión la que dejó Humberto Ak'abal en mí. Más deschabetado y bromista que la Menchú, pero igual de sabio y profundo en sus apreciaciones.

Mi padre me enseñó a leer, a descifrar los relámpagos del cielo. Por él supe distinguir cuándo los relámpagos anuncian tormenta o anuncian temporal; cuándo señalan que el invierno está a punto de acabar...

Esta es una paráfrasis de las palabras con que Humberto Ak'abal inició su ponencia en el Tercer Encuentro de Intelectuales ChiapasCentroamérica. Después habló de las maneras que los indígenas tienen para hacer poesía. Para los quichés el lenguaje reproduce con sus sonidos las características de los objetos que nombra o que señala. De ahí que referirse a un pájaro es reproducir su canto... Dice así un poema de Humberto:

\section{CHI'IK \\ De Plumaje café \\ y anaranjado \\ Ch'ik, ch'ik, ch'ik, \\ "está llamando al agua" \\ ch'ik es su canto \\ ch'ik es su nombre. \\ Salta cantando \\ entre retoños de milpa.}

Es el pajarito

pedidor de aguaceros.

Lenguaje onomatopéyico, poesía onomatopéyica, como la poesía fresca de las primeras etapas de la cultura humana. Pero fue en conversaciones posteriores que yo retomé el tema del desciframiento o. lectura de los signos que aparecen escritos en el cielo. Personalmente me interesa penetrar en esas otras formas de lectura que puede uno hacer en la naturaleza y en el cosmos. Por eso, le insistí a Humberto que me hablara de ello. 
En mi pueblo los mayores pueden leer e interpretar el canto de ciertos pájaros o el aullido de los coyotes... Fijate que los coyotes hasta pueden anunciar desgracias. Por ejemplo, una vez bajaron de la montaña dos coyotes peleándose... Llegaron hasta el centro del pueblo, destrozándose a mordiscos y aullando lastimeros... Uno de los ancianos dijo que se aproximaban tiempo dificiles para el pueblo. Y fue cierto... a los pocos meses el ejército de Guatemala hizo en la zona una de las más grandes masacres. Los aullidos de los coyotes pueden anunciar las guerras o los tiempos malos, pues...

Algunas vibraciones han de percibir los animales de modo que pueden "predecir" con sus sonidos o con sus comportamiento sucesos que habrán de ocurrir en el futuro. Algo así como pasa con los terremotos "anunciados" por las hormigas o por los caracoles de las peceras. Cuando va a ocurrir un sismo, dicen algunas gentes que las hormigas salen de sus cuevas en cantidades inusuales y adoptan comportamientos erráticos, como si se volvieran locas... Lo mismo pasa con los caracoles: empiezan a subir todos a la superficie y a querer hasta salirse de la pecera.

Humberto Ak'abal continuó con su relato sobre algunos poderes especiales de sus parientes:

Mi tio abuelo es una especie de sacerdote o shamán en Momostenango y en algunos pueblos de los alrededores. El es el encargado de realizar ciertas ceremonias; por eso, tiene una bolsita de cuero en la que guarda 260 piecesitas: unas son piedritas... así, del camino; otras, son pedacitos de hueso, y otras son chibolitas de jade... son 260 porque ese es un número mágico: equivale al calendario lunar de 260 días.

Un día mi tío abuelo tenía que hacer una ceremonia en un pueblo de la montaña, y me dijo que fuera con él... Yo entonces era un patojo de unos 13 años; pero me acuerdo bien. Ibamos en el camino cuando nos salió una culebra... de las pocas venenosas que hay en la región. Como la culebra no nos dejaba pasar, yo agarré un palo para tirárselo; pero mi tío abuelo me dijo: 'Espérate; la culebra no nos deja pasar por que nosotros hemos invadido su territorio. Deja que hable con ella'. Mi tio abuelo se acercó al animalito y, en nuestra lengua, le dijo: 'Hermana, si 
estamos molestandote, perdonanos... pero tenemos que pasar por esta vereda para ir al pueblo y hacer una ceremonia; por favor, dejanos continuar'. La culebra se le había quedado mirando bien quietecita; después... dio la vuelta y se metió en el monte.

Nosotros seguimos caminando. Habia llovido bastante y teníamos que pasar encima de un troncón para atravesar un río... no muy ancho pero sí bastante hondo... Ibamos encima del tronco cuando a mi tío abuelo se le cayó el saquito con sus talismanes. Yo, entonces, me apuré a agarrar una vara larga para sacar el saquito del agua. Mi tío abuelo me dijo: '-Mirá, la correntada está fuerte; y si vos metés la vara, más vas a revolver el agua. Mejor dejá; si la bolsita está en el fondo... ya la vamos a sacar. Me pidió que lo dejara solo... así que se alejó unos metros. Yo me quedé junto al río, pero viendo lo que hacía mi tío abuelo.

Puso a quemar copal en cuatro esquinas, formando un cuadrado... Se sentó en medio y comenzó a rezar algo extraño. Al poco rato me doy cuenta de que el agua del río, debajo del tronco, empezó a borbollar como si estuviera hirviendo... La bolsita de mi tío abuelo subió hasta la superficie. Y entonces él me dijo: - Ahora sí, sacala con la vara'.

Gracias a esos "milagros", el tío abuelo de Humberto Ak'abal nos recuerda a cualquiera de esos santos cristianos representados por la imaginación popular hablando con un lobo (caso de San Francisco de Asís) o predicándole a los peces de un lago, asomados a la superficie para escucharlo (caso de San Antonio de Padua).

Una misma "virtud" quizás poseen los santos cristianos y los santones paganos (de antes y de ahora). Una "virtud" que tiene que ver - tal como apuntábamos antes-con poderes explicables racionalmente, como el de quienes pueden dormir a un escorpión o a una culebra con la sola fuerza hipnótica de su mirada, o con poderes mágicos, llámeselos a estos milagrosos o sobrenaturales.

Por su parte, Humberto Ak'abal no posee quizás poderes tan impactantes como los de su tío abuelo; pero, a cambio, tiene el poder - también mágico, demiúrgico- de dar vida con sus palabras a realidades nuevas. El es un shamán, un sacerdote escriba, según lo entienden así sus propias gentes de Momostenango. Su 
misión en el mundo es conjurar —con el poder de su palabra poética y narrativa - a los espíritus, convocar a los duendes que yacen dormidos detrás y en el fondo de las cosas. A Humberto Ak'abal le toca algo así como provocar metamorfosis: hacer que a la larva y al gusano le salgan alas para que puedan emprender el vuelo, transformados, por fin, en mariposas.

\section{Los brujos más poderosos}

Salvador Marroquín es un musicólogo connotado y un apasionado investigador de las culturas autóctonas. El me decía que aquí en El Salvador hay gentes con facultades y poderes increíbles, heredados de las antiguas culturas. Sólo que esos magos y brujos ejercen en círculos cerrados, vedados para la mirada del profano.

Aqui en el país existen los brujos más poderosos de América. Un amigo mío me cuenta que él tuvo la suerte de asomarse un poco a esos círculos, y pudo darse cuenta de alguno de sus poderes.

Uno de esos brujos le dijo a mi amigo: '-Veni, vas a ver algo que sólo se ve en las películas o en los sueños; algo que parece imposible'... Y lo llevó al lado de un gran farallón. '-Voy a volar', le dijo. Se encaramó encima de la gran peña y se lanzó al vacío. Al rato, estaba al lado de mi amigo, tocándole el hombro: ‘Ya viste?'

Vuelo real o efecto de algún alucinante, el hecho es que para Chamba Marroquín aquí en el país los brujos le hacen la competencia a Superman y al Hombre Araña. Yo estoy seguro de que, efectivamente, aún desconocemos gran parte de lo que la mente humana o esas energías maravillosas que nos rodean, son capaces de realizar. Para los no iniciados, para los que nos acercamos al borde de esos misterios, lo menos que podemos hacer es mostrar un gran respeto; aunque tampoco está de más un sano y distante escepticismo.

Yo supe de alguien -continuó relatándome Salvador Marroquín- que podía hacerse chiquito, chiquito... Un día le dijo a unos cheros: '-Me voy a meter en esa botella'. $Y$ al rato apareció así chiquitio, dentro de una botella... de esas como de Tic-tack. Pero uno de los cheros que estaba ahi hizo la gracia de 
tapar con la mano la botella... cuando ya el otro volvió a su tamaño normal, resultó bien encachimbado con el gracioso: 'Puta, cabrón, ya me estabas asfixiando!'.

Salvador Marroquín no es de los crédulos ingenuos que se va a andar creyendo todo lo que le cuentan; por eso, es más que aleccionador su testimonio. Incluso, él mismo ha sido testigo de alguna "pasada".

A mí también me pasó algo raro una vez... Yo estaba estudiando en la universidad, allá por los setenta... Un grupo de compañeros fuimos a chotear y a fregar cerca de Panchimalco. Ibamos caminando cuando a algunos nos dio sed y decidimos pedir agua en una casita que se veía a un lado del camino. Entramos por la veredita... y unos chuchos bravos salieron a recibirnos. Después, un señor bien atento, espantó a los chuchos y nos dio el agua que le pedíamos... Platicamos un rato con él, $y$ después nos fuimos.

Me llamó la atención algo: el señor no parecía de por ahí: chelito, chapudito, con una barba blanca, algo rala... porque ya se veía bastante señor.

Meses después, yo estaba trabajando en el Ministerio de Educación... Ahí, entre un grupo de cheros conté sobre el tour que habíamos hecho a Panchimalco y el encuentro con el señor de la casita, al lado del camino... Uno de los empleados del Ministerio se sonrió disimuladamente mientras yo les contaba la aventura... A mí no dejó de molestarme la risita maliciosa, pero me hice la vieja fresquera.

Después de la reunión social esa, el señor de la risita me llamó aparte y me dijo: '-Mire, don Chamba, yo me reí cuando usted estaba contándonos de su excursión por Panchimalco, porque yo soy de ahí... y me conozco todo eso. El volado es que no ha habido nunca una casa donde usted dice; ni ha existido tampoco un señor como el que usted vio... ; a usted le han hecho una burleta esos brujos de Panchimalco!'.

Sean o no los más poderosos de América, los brujos de El Salvador saben hacer sus cositas; y quién sabe si hasta dejarían mal parado a Mandrake el Mago... 


\section{La conversión de humanos en animales}

El libro Mitos y leyendas de los pipiles de Izalco es una auténtica joya. Su autor es Leonhard Schultze Jena, uno de los traductores del Popol Vuh. La labor de este sabio austríaco fue valiosísima aquí en El Salvador por varios respectos: primero, porque es una colección de testimonios que da cuenta sobre la visión del mundo pipil; y segundo, porque se hace esa recopilación en un año clave, 1930: todavía la etnia y la cultura de los izalcos no han recibido el castigo y la represión de 1932. Simbólicamente, pues, Mitos y leyendas de los pipiles de Izalco es casi un testamento de la cultura pipil. Toda esa sencilla pero también fresca poesía indígena aparece retratada ahí... quizás por última vez.

Me interesa ahora consignar algunos pasajes de la obra, en orden a hacer ver el poder especial que tienen algunas personas $y$ animales de ser, al mismo tiempo, o de convertirse en otras personas o animales. Dice así un texto:

(...) Cuando vio un venado y le tiró con una escopeta.

Vio que había dado en el blanco y lo siguió hasta donde terminaba de gotear la sangre. Al seguir su rastro llegó a un pequeño arroyo.

Alli lavaba una muchacha; le preguntó: ¿Has visto pasar a un venado?

Ella le respondió: - Nada ha pasado por aqui... Aqui tengo la cinta de mi pelo, quizás ya la viste.

Entonces ella la levantó de una punta, y él vio que goteaba sangre (...) (p. 30).

Luego, la muchacha-venado llevará al joven cazador al interior de una montaña y allí cohabitará con ella durante diez días (mágicamente, diez años). La muchacha dará a luz a veinte venaditos, y así el cazador repondrá los animales que mató en sus cacerías pasadas.

Otro texto nos dice:

Por eso, cuando el muchacho dijo que él desearía todo, se dio cuenta que la serpiente misma era el Viejo: que la serpiente se convertiría en el Viejo (p. 40). 
(...) Le dio huesecitos de cada uno y también plumitas y dijo: "-Esto es para el caso de que tú quisieras algo que necesites: con una plumita verás que podrás volar.

Verás que te puedes convertir en cualquier pájaro que desées. (P. 41).

El sueño del ser humano de poder transformarse en cuanto pájaro quiera para poder volar: esa es una de las virtudes que ciertos magos regalan a sus protegidos. El mismo mago del texto puede convertirse en serpiente.

Finalmente, otro texto dice lo siguiente:

Vio que habia ancianitos y ancianitas; que tenían una cocina.

Vio que ellos para salir volando se desnudaban.

Para poder salir volando vio que habia un arbolito. Este cuando ya pueden volar- lo circundan hasta llegar a la cima.

Describian tres círculos para llegar a la cima; después podían volar libremente (asi es como salen y como entran).

Después de descansar un rato, salen de nuevo a la cima.

Al haber descansado un poco sobre la copa del arbolito, vuelven a volar, haciendo los mismos círculos tres veces.

Al llegar le dan al viejito y a la viejita lo que traen, y preparan la comida.

Alli está un toro. El muchacho vio que le sirvieron a él primero; después al viejito y a la viejita, y por último comen los demás.

Vio que el toro podia transformarse en cualquier cosa que deseaba, y que también podía hablar ( $p p$. 38-39).

Mundo este en el que no existen barreras entre los seres y las cosas. Porque casi, casi se puede tomar la forma o la personalidad del animal o de otro ser que se desee. Mundo surreal en que los seres humanos son parte animal y parte gente. Mundo insólito, pues, que recuerda a Minotauros, a Centuros, y a Satíricos de la imaginaría griega; o a los dioses con cuerpo humano y cabeza de chacal, de vaca o de halcón, propios del panteón egipcio; o los 
dioses híbridos de humano y elefante, en las representaciones hindúes.

Pero, en las concepciones indígenas esta posibilidad de intercambio entre lo humano y lo animal y viceversa, está conectada con una creencia muy antigua: el nahualismo. Según esta creencia cada persona tiene un nahual, es decir, un alter ego (un otro-yo) que puede ser un animal o inclusive una cosa. Con este otro ser (animal o cosa) gemelo, el humano comparte su suerte, de modo que si se hiere o se mata al ser humano, lo mismo le ocurre a su nahual; o viceversa.

Una leyenda bellísima en esta línea es la de Tecun Umán, el cacique cakchiquel que se enfrentó con Pedro de Alvarado. Cuenta esa leyenda que el nahual de Tecún Umán era un quetzal y que volaba sobre la cabeza del cacique mientras este combatía frente a frente con el conquistador español.

El jefe cakchiquel parecía invencible porque cuanto ataque hacía Alvarado era esquivado por su contendiente, quien, por su persistencia y agilidad, parecía ser un ave desplegando sus alas y saltando de un lado a otro como si pudiera volar. De alguna manera el capitán español se dio cuenta del misterioso nexo entre su enemigo y el quetzal que lo sobrevolaba; de modo que, con su lanza, apuntó al ave y la abatió. Inmediatámente, Tecún Umán bajó la guardia y pudo ser ultimado con facilidad.

Murió Tecún Umán al morir su alter-ego, su quetzal... Hermosísima alegoría sobre la muerte de las culturas indígenas ante el embate español: al matar al nahual de esas culturas - los brujos capaces de convertirse en los animales que quisieran - fue posible abatirlas a ellas como un todo.

Pero también es posible hacer otra lectura de esa misma muerte de las culturas indígenas americanas: mataron al guerrero, pero no pudieron abatir a su nahual; esos disminuidos y pobres sucesores de los antiguos sacerdotes aún conservan el poder de transmutarse en sus nahuales, escapando así de los perseguidores.

Me viene a la memoria el negro Mac Andall de El Reino de este mundo, de Alejo Carpentier; este negro zamarro era capaz de convertirse en patơ y otros animales para burlar la-vigilancia de 
sus enemigos.

Pues bien, la creencia en la posibilidad de metamorfosearse en animales puede ser interpretada como síntoma del atraso cultural en que yacen sumidas muchas gentes. $Y$, en parte, es cierto que a menor desarrollo intelectual y social, corresponde una mayor adhesión a explicacionès ingenuas, simplistas y fantasiosas sobre los fenómenos de la realidad.

Pero, por otra parte, también es cierto que la vigencia de esas explicaciones mágicas es prueba de que entre ciertos sectores de la población hay todavía un lugar para la magia y para la fantasía. Ahí, en ese ámbito donde todo puede suceder sin temor a romper las leyes más sagradas de la lógica y de la física; ahí, en ese círculo -no necesariamente diabólico porque eso huele a muerte y a descomposición- en que quedan anulados el tiempo y el espacio; ahí hay un lugar para el asombro y para el encantamiento, para ese dejarse llevar por el sabroso morbo que producen los espantos y los aparecidos.

Y ese reducto del sueño donde uno puede volar o convertirse en cualquier animal a discreción, es una muestra de que esta civilización occidental, supertecnificada, ultrarracionalizada, despiadada y cínica, aún conserva un hálito de las antiguas culturas. Aún tenemos todos un nahual común: una bestezuela no domesticada que en unos explota en las más crueles formas de violencia, y en otros se explaya en las más insólitas fórmulas para la evasión improductiva o para las más fértiles y creativas expresiones del arte y de la poesía, sean estas de corte popular o erudito.

Quiero seguir ilustrando con testimonios estas virtudes y poderes mágicos que poseen algunas personas. Licantropía es la facultad del humano de convertirse en lobo. Por eso, si algún nombre genérico habremos de dar a quienes pueden convertir a otros o convertirse ellos mismos en animales es el de zooantropía.

En el Popol Vuh se nos cuenta que los gemelos Hunahpú e Ixbalanqué fueron capaces de transformar mágicamente en animales a sus hermanastros mayores:

(...) Y Hunahpú e Ixbalanqué les contestaron: -Desatad vuestros calzones, atadlos debajo del vientre, dejando largas las 
puntas y tirando de ellas por detrás, de ese modo podréis andar fácilmente. Así dijeron sus hermanos menores.

-Está bien, contestaron, tirando la punta de sus ceñidores; pero al instante se convirtieron estos en colas y ellos tomaron la apariencia de monos. En seguida se fueron sobre las ramas de los árboles, por entre los montes grandes y pequeños y se internaron en el bosque, haciendo muecas y columpiándose en las ramas de los árboles.

Así fueron vencidos Hunbatz y Hunchouén por Hunahpú $e$ Ixbalanqué; $y$ sólo por arte de magia pudieron hacerlo.

(...) Pero fueron convertidos en animales y se volvieron monos porque se ensoberbecieron y maltrataron a sus hermanos. (Pp. 86-88).

En este caso, dos muchachos son transformados en monos porque habían sido soberbios y habían maltratado a sus hermanos menores. Estos, pues, podían ejercer sobre otros el poder de la zooantropía.

Sin embargo, vamos a conocer otros casos de conversión en monos o en animales, pero no por castigo sino por efecto de una rara y misteriosa habilidad. Para tal efecto entrevisté a don Jorge García, conocido como don Gumersindo en YSUCA. El me informó sobre algunas experiencias que había tenido durante su infancia y sobre anécdotas que le habían contado algunos parientes y amigos.

Eran los años 30, más o menos... Yo viajaba con mi abuela desde Cuscatancingo a Mejicanos en la madrugada... Ibamos al molino como a las cuatro de la madrugada; y todo eso era todavía una zona rural... Pero iban grupos grandes de gentes; no se atrevian a pasar solas las personas. $Y$ algunas veces nos llevaban a nosotros, los chiquitines. Entonces, en unos bambuáles - había unos bambúes enormies- salian esos monos... micos araña que llaman. A media calle. Se cruzaban delante de nosotros y chillaban... Unas nativas de ahi decian: '-No tengan miedo, porque esa es la fulana, aquel es mengano o sutano... Lo que quieren es jugar con nosotros... iPasemos!' 
Yo interrumpo a don Jorge y le digo que aún ahora se cuentan cosas parecidas. Mi sobrino dice que le han rẻlatado algo divertido: unos señores se transforman en monos; uno de ellos tiene una corona de oro en los dientes; así que cuando se convierte en mono, todos ven al animal con la misma corona de oro que tiene el señor.

Don Jorge continúa su relato:

Del lado de San Antonio Abad... en las faldas del volcán de San Salvador había gentes que podían convertirse unos en un animal, otros en otro... Por ejemplo, una señora dijo un día: - La Maria Chon me está robando los huevos y las gallinas porque se convierte en gato de monte; pero ya la voy a fregar yo...' Y la tal señora se convertía en cuche de monte para ir a robarle huevos y gallinas a su enemiga la María Chon.

Era un solo relajo ese: unos volviéndose una cosa; otros... otra. Incluso había como una especialización: por Cuscatancingo las gentes se volvían monos... por San Antonio Abad y otras partes del volcán... se transformaban en gatos y cuches de monte.

Hubo una anécdota contada por don Gumer que me llamó especialmente la atención:

Por el lado de Zacatecoluca... viajaba una tía mía. Ella llegaba adonde una comadre que tenía varios niños... Una vez, una de las muchachitas le dijo a la señora: '-Mamá, ¿hago "chump"? ¡Yo quiero hacer "chump"! —iVaya, niña, no esté molestando! - ¡Yo voy a'cer "chump", mamá! Y la niña se metió detrás de la casa... al poco rato salió un chompipito bailando y haciendo ;chump!... jchump!... La niña es la que se convertía en guajolote, según me cuenta mi tía.

Igualmente simpática es esta otra "pasadita":

Cuando yo era cipote, un compañero de colegio me narraba que ahi por Izalco, donde él vivia, había un chero que se tomaba sus tragos... Y entonces, en las esquinas donde llegaba ya borracho daba un vueltegato... asi, detrás de una casa, por un monte... y salía convertido en cabro... De repente daba otro vueltegato el cabro y ya era el mismo hombre de antes. 


\section{Corolario: el animalito que puede convertirse en duende}

Luego, don Gumer me contó otras aventuras que tienen que ver con las consabidas de duendes como la Cihuanaba, el Cipitío y el Cadejo. Yo creo que se trata de otros nahuales... En el caso del Cadejo es claro: hay un animalito de esos que protege a las mujeres y otro que protege a los hombres. El Cipitio es otro duende que parece el ángel guardián de las muchachas bonitas. Y la Cihuanaba es la que asusta a los parranderos nocturnos. Según don Gumer, la Cihuanaba les "sale" sobre todo a los tunantes... esos que vuelven ya noche a sus casas después de haber estado en una fiesta o en los brazos de una mujer. Lo interesante es el trasfondo de este duende.

Cihuanaba quiere decir la mujer llorona -creo que viene de Cihua $=$ mujer; y nicúa $=$ llorar $;$ nigua, anagua $=$ llorona- Es quizás la misma Llorona de México... Fíjese que es una palabra emparentada con guanaba o fruta llorona... Se le dice asi porque cuando está madura echa una semillita muy fina que al caer suena como gotas de llovia o de llanto... A mi me sucedió una vez que habiamos ido a una finca, a una fiesta. Estábamos debajo de unos guanabos, palos de guanaba, cuando alguien dijo '-iQuitense de ahi por que están tirando arena'... Y de véras que se oía: schiiihhh... schiiihhh... iPero eran las semillas de las guanabas que nos estaban cayendo encima!

Cihuanaba, pues, es la mujer llorona que asusta a los tunantes y transnochadores. En la cultura nahua se la conocía como Cihuehuetl, una princesa que, por adúltera, fue condenada a vagar por las barrancas, llorando su pecado. Parece que la leyenda tiene que ver con la costumbre pipil de que las "alegradoras", las prostitutas no podían ejercer su profesión en los poblados; tenían que hacerlo en las afueras... junto a los ríos y las barrancas. De ahí quizás que el espíritu de alguna de ellas se quedara vagando hasta ahora, cobrando con el susto, el momentáneo placer de haberla llevado en ancas mientras era una hermosa mujer.

Don Gumer tiene su versión sobre la Cihuanaba:

Algunos dicen que la leyenda de la Cihuanaba tiene su base real en un animalito... Recordemos que la Cihuanaba casi siempre sale de noche en los ríos... Llama a la gente, se tira unas 
grandes carcajadas y hace iplash!, iplash! en el agua con sus grandes chiches. Pues resulta que el mapache, ese animalito con antifaz negro, pesca en los ríos durante la noche. Ahí anda metiendo sus manitas debajo de las piedras para agarrar cangrejos y camarones... y posiblemente esos schiiittt... schiiittt con que llama la Cihuanaba no sean más que los silbidos que da el mapache...

A veces, algún cangrejo agarra con sus tenazas los deditos del mapaches... y este chilla y chilla de dolor. Esas han de ser las grandes carcajadas que se tira la Cihuanaba: cuando el mapache agarra un cangrejo, le pega contra las piedras para destrozarlo y asi podérselo comer... Son los iplash!, iplash! de las chiches de la Cihuanaba.

También los espíritus errantes tienen su nahual, su animal vivito y coleando... en este caso, el mapache puede ser el alter-ego de la Cihuanaba. En las noches oscuras, alguien con sus tragos encima y alertado de que por esos lados asustan, pues muy probablemente confundirá los ruidos que hace el mapache con los gritos de la Ciguanaba y se irá corriendo a contarle a sus gentes que lo asustaron allá... por la barranca honda.

12 de octubre de 1993. 